\title{
The Planning Process: \\ Lessons of the Past and a Model for the Future
}

\section{Ray Bromley}

In examining the planning experiences of most countries, the overwhelming impression is one of frustration and ineffectiveness. Planning and planners have simply not lived up to expectations, and both critiques and recommendations for improvements abound (e.g. Waterston 1965; Griffin and Enos 1970; Faber and Seers 1972; Caiden and Wildavsky 1974). Behind the facade of technical precision, the development planner seems to lack effective understanding of his own society, the ability to predict future trends, and the means to ensure that plan implementation takes place. It seems as if every sentence we hear or read beginning with the words "The planners ..." ends with either criticism or ridicule. The 1950s and 1960s were unusual decades, in that most countries and international organisations gave high priority and considerable resources to econocratic development planning, believing that through sophisticated planning they would resolve their problems and create a better world. Now, optimism has largely been replaced by cynicism, and planners have come under attack from all sides, becoming the 'whipping boys' of politicians, consultants, academics, and large sectors of the general public.

This article is written in the belief that contemporary planning in most countries and situations is inadequate and sometimes even harmful, but that suggestions to 'abolish planning' are fundamentally wrong. My objective is to present a viable conception of and role for planning, and to suggest a model which can serve as a basis for development planning in the future. Very little of what I will say is new. My only claim to originality is that I give different emphasis to each issue and activity than other authors, producing a recipe which contains virtually all the same ingredients, but mixed in different proportions and in a different order.

\section{What is planning?}

In broad terms, planning is concerned with defining and achieving objectives for the future, so that the changes occurring in particular societies and nations are not determined simply by fortuitous or external circumstances, but through the purposive decisions and actions of some or all of their inhabitants. It must be recognised, however, that perfect, comprehensive planning assumes the divine powers of omniscience, omnipresence and omnipotence, and that such a situation is clearly impossible. It is obvious, therefore, that planning can only be conducted for a limited range of activities and for a limited time period, and that it may be little more than "an ideal of rational reorganisation, where less is wasted through neglect and confusion, or the pursuit of incompatible ideals" (Leys and Marris 1971: 270). No society can assume perfect knowledge of the present, total autonomy and control over its own affairs, the ability to predict future trends and events, or a universal consensus on desired changes for the future (see Bauman 1967). We live in an uncertain, interdependent, and frequently conflictive world, and it is absurd to believe that a society can precisely design and create its future. At best, at the societal level, planning is an attempt to define, and to move in, a desired direction. It must face internal dissent and apathy, and external opposition. Development planning is a task much more dificult than that normally faced by the architectbuilder of a house, or the designer-manager of an industrial production line, so that a simplistic design-execute or plan-implement model is bound to fail.

Development planning is a venture into the unknown, creating situations and problems which have never previously existed in a given context. Such a process necessitates a capacity for continuous action, monitoring, response and innovation, rather than simply the preparation and execution of a master plan. These requirements have been recognised by many city-planners dissatisfied with the traditional master plan approach, and a broad concept of 'action planning' (see Koenigsberger 1964, 1968; Wakely, Schmetzer and Mumtaz 1976) has resulted. The action planning approach is a great advance over rigid master planning, but action planning roles and activities have been inadequately specified. There is a grave danger that action planning will degenerate into 'disjointed incrementalism' (Braybrooke and Lindblom 1963: 81-143), a model possessing admirable flexibility, but little capacity to deal with a serious depression or sudden crisis. The rapidity of change and the 
necessity to consider planning as a trial and error learning process' rather than 'the design and creation of Utopia', have also been recognised by a group of North American authors. This "planning as societal learning school', headed by such figures as Michael $(1968,1973)$, Dunn (1971), Friedmann (1973) and Bell (1974), has produced works of considerable merit in the analysis and prognosis of technological and social change, but has not provided an adequate model for the planning process.

\section{What is new about planning?}

In terms of definition, contemporary planning is no different from the planning conducted by our forelathers. Planning has always been concerned with defining and achieving objectives for the future, and the significant differences between past and present planning lie in professionalism and division of labour, rather than in the basic task. In recent years, planning has been professionalised, and planners are expected to undertake specialised training, to acquire qualifications, and to possess skills which are not known to the common man, or even to many public administrators and politicians. Naturally, professionalisation is a mixed blessing. On the one hand, technical expertise is increasingly necessary in a sophisticated world, but on the other hand, as Illich $(1971,1975)$ describes for teachers and doctors, professionalism can foster pretentious attitudes, the creation of techno-bureaucratic vested interest groups, and the increasing isolation of professionals from those they are intended to serve. In terms of division of labour, most countries have imposed a sharp dividing line between those who write plan documents (construct plans), and those who implement them, and this division is often enshrined in separation of responsibility, not only between professionals, but also between government departments. Separation can easily result in isolation, and many writers have pointed to inadequate plan implementation as the fundamental impediment to effective planning (e.g. Waterston 1965: 293-370; Gross 1967; Cacho 1975).

The professionalisation of planning and the division of labour between those who write plans and those who implement them have institutionalised a 'narrow view' of planning. Narrow-planning is simply the preparation of plans; the writing of plan documents and the drawing of maps and diagrams for planning purposes. It is usually the task of professional planners, and takes place in specialised planning offices, or even in 'Ministries of Planning'. Narrow-planning tends to be technocratic, rarely has any effective form of public participation, and often only marginally involves the participation of society's leaders. It is usurally a discontinuous process focused on documents rather than real-world changes, and hence it is often dubbed 'paper planning'. It easily degenerates into "pseudo-planning" (Seers 1972), or "a symbolic charade" (Bromley 1977). At worst, narrowplanning is simply a waste of time, money and personnel, tending to postpone or even prevent change, rather than to bring it about.

\section{An alternative to narrow-planning}

If we are to escape from the evils of narrowplanning, we must return to our original ideal of planning as "defining and achieving objectives for the future', establishing a concept of 'broadplanning' which facilitates this process. Broadplanning can be considered as the integral process of deliberate societal change. It is achieved through the analysis of relevant information including consultations with all relevant interest groups, the preparation of forecasts, the selection of objectives, the construction and authorisation of plans of action, the implementation of these plans, and the monitoring, evaluation, and progressive modification of the plans, implementation strategies, and results achieved. Broad-planning is necessarily a continuous, integrated process, affecting and involving a substantial part of society, and particularly involving those who hold political and economic power. Because most of those involved do not have a professional training in 'narrow-planning', broad-planning can avoid excesses of technocracy and utopianism, and can facilitate mobility of personnel between institutions concerned with different parts or levels of the planning process.

The broad-planning model shown in Figure 1 is intended to avoid the drawbacks of most contemporary development planning, and to present a process which is more intelligible than the available literature on 'action planning' or 'planning as societal learning'. The model presents a sequence of activities which, once begun in box 1 , develops into a continuous process, with an ongoing flow of information, and sometimes also of instructions, from box 1 to box 10 , and with feedbacks of information and instructions converting the essentially linear sequence from 1 to 10 into a series of interrelated loops. Individuals and departments can specialise in particular sections of the process, and yet all parts of the process should be considered as part of a single, 
Figure 1 Proposed model for a continuous, integrated planning process

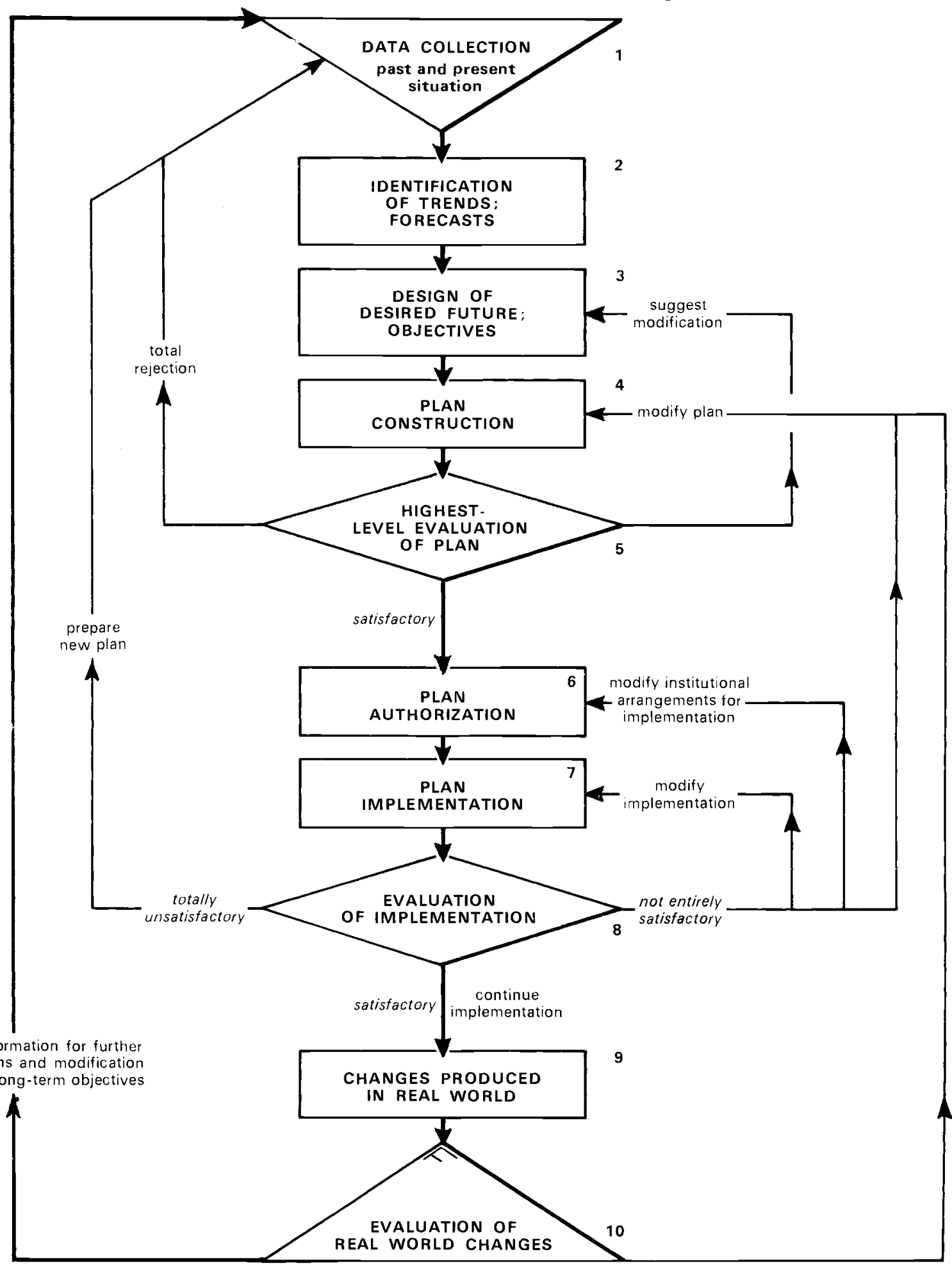


closely integrated whole. The model is deliberately simple as it must be comprehensible to all politicians and government officials, and to a substantial proportion of the population, if it is to be successful.

The model as presented facilitates the close integration of annual budgeting cycles into the planning process, and permits the presentation of quarterly and annual reviews of progress, and lists of projects and estimated completion dates. There is no absolute requirement for a single major plan document, but the process does not preclude the preparation of annual or medium-term (three to 10 year) plans. For most countries, mediumterm plans should be only for three or four year periods, and should either be coordinated with annual budgets and plans to produce a rolling plan system, or with the electoral cycle if government changes are usually regular, as in Colombia and the United States. Even in relatively unstable contexts, however, short- and medium-term plans should be based upon long-term 'generalised objectives" so as to avoid a concentration upon capital intensive projects yielding quick returns at the cost of neglecting more fundamental longterm transformations and distributional issues. The model does not impose any particular institutional structure for planning, but the necessity of closely interlinking plan construction with plan implementation suggests that both operations should normally be conducted within the same institutions, working on particular sectors (e.g. in exceutive Ministries), and at the national, regional, and local levels. Inter-sectoral and inter-regional allocation issues should normally be resolved mainly at the highest level of national government, the Presidency or Prime Minister's Office, and the Cabinet or Ruling Council, supported by a small advisory Planning Secretariat.

A major feature of this model is the emphasis given to data collection and evaluation, including the consultation of relcvant interest groups, the identification of trends, forecasting, and the monitoring of ongoing projects and programmes. The weakness of these activities in many contemporary planning systems is as grave a deficiency as the virtually total separation of plan construction and plan implementation. The title of Stolper"s (1966) work Planning withont Facts, is a reflection of the realities of development planning in most parts of the world. Information is either non-existent or virtually useless, uselessness bcing a function of the collection of irrelevant data, long delays in data processing and publication, or simple inaccuracy of information. Project evaluation is usually impeded by the absence of baseline or control group data, and major data sources such as censuses, national accounts statistics, and topographic maps of ten seem to be designed more for international comparisons and foreign researchers than for planning purposes. There is a special nced for a reorganisation of data collection and processing in most countries, so that the information collected can be more aceurately attuned to the needs of efficient development planning, and so that data can be presented more quickly and disaggregated more easily to give information about distribution by local areas and specific social groups.

\section{Limitations of the model}

Though the proposed model can help to improve the quatity of decision making and plan implementation, and can ensure interaction between different interest groups, its adoption cannot resolve the fundamental issues of political power and participation. Most of the issues left unresolved by the model are those which condition the objectives of planning itself. No planning system can resolve the problems of a country run by a mentally unbalanced dictator, or a country in the throes of civil war. An effective planning system helps those in power to achieve their objectives, but it does not decide who holds power or what their political ideologies and objectives should be. The model does not guarantee large scale "popular participation in planning, and such participation is probably impossible unless there is a high degree of administrative and fiscal decentralisation, and a predominance of "social property" rather than private enterprise or state ownership. Similarly, the model does not resolve the issue of whether planners should adopt politicised advocacy roles (see Kasperson and Breitbart 1974), or should attempt to wear a cloak of political neutrality, simply servicing the objectives of politicians. Advocacy planning implies great enthusiasm and commitment on the part of planners, but it also implies great instability in the civil service whenever there is a change of government. The model also fails to tell us what balance to give to indicative and mandatory measures, or to material and moral incentives, and it does not help us to resolve problems of corruption in government. In a sense, therefore, this brief article dodges the major issues of development policy and merely presents a highly generalised model, integrating information collection and transter, plan construction, and plan implementation. The model is applicable to all major types of development planning (economic, social, 
spatial and physical), and to planning at the national, regional and local levels. It can be used both for comprehensive planning of countries or smaller areas, and for the planning of selected programmes and projects without an all-embracing comprehensive plan. In most countries, comprehensive plans are both technically and politically naive (see Leys 1972: 74; Killick 1976). Issues of inter-sectoral and inter-regional allocation, and long term societal objectives, must be determined through an esentially political process with technical advice, rather than through an essentially technical process subsequently presented for polical approval. There is no single optimum development strategy for a given country. There are nany possible optima, each favouring a particular balance of interests and representing a different set of priorities. Planning is essentially a process of policy definition and implementation, and policy is both politically determined and has explicit or implicit political objectives.

\section{References}

Bauman, Zygmunt, 1967, "The Limitations of Perfect Planning, in B. M. Gross (ed.), Action under Plonning, McGraw-Hill, New York

Bell, Daniel, 1974, The Coming of Post-Industrial Society, Heinemann, London

Braybrooke, David, and Charles E. Lindblom, 1963, A Strategy of Decision, Free Press, New York

Bromley, R. J., 1977, Development and Planning in Ecurdor, Latin American Publications Fund, London

Cacho, C. P., 1975, 'The Road to Plan Implementation, Finance and Development, 12, 4

Caiden, Naomi, and Aaron Wildavsky, 1974 Planning and Budgeting in Poor Countries, John Wiley, New York

Dunn, Edgar S., 1971, Economic and Social Development: A Process of Social Learning. Johns Hopkins University Press, Baltimore

Faber, Mike, and Dudley Seers (eds.), 1972. The Crisis in Plaming (2 vols.), Chatto and Windus, London

Friedmann, John, 1973, Retracking America: A Theory of Transactive Planning, Anchor Doubleday, New York

Griłtin, Keith B., and John L. Enos, 1970, Planning Development, Addison-Wesley, Reading (Mass.)
Gross, Bertram M., 1967, Activating National Plans', in B. M. Gross (ed.), Action under Planning, McGraw-Hill, New York

Illich, Ivan, 1971, Deschooling Society, Calder and Boyars, Edinburgh

Illich, Ivan, 1975, Medical Nemesis: the expropriation of hiolth, Calder and Boyars, London

Kasperson, Roger E., and Myrna Breitbart, 1974. Participation, Decentralization, and Advocacy Planning. Resource Paper no. 25; Association of American Geographers, Commission on College Geography, Washington D.C.

Killick, Tony, 1976, 'The Possibilities of Development Planning', Oxford Economic Popers, NS, 28

Koenigsberger, Otto, 1964, 'Action Planning', Jommal of the Architectural Association, May

Koenigsberger, Otto, 1968, 'Planning for Rapid Change', Report of Proceedings: Town and Country Planning Summer School: Queen's University of Belfast, 1967, Town Planning Institute, London

Leys, Colin, 1972, 'A Conception of Planning?' in M. Faber and D. Seers (eds.) The Crisis in Ploming, vol. 1, Chatto and Windus, London

Leys, Colin, and Peter Marris, 1971, 'Planning and Develcpment', in D. Seers and L. Joy (eds.), Development in a Divided World, Penguin, Haimondsworth

Michael, Donald N., 1968, The Unprepured Society: Plamning for a Precarions Future, Harper and Row, New York

Michael, Donald N., 1973, On Leorning to Plonand Planning to Learn, Jossey-Bass, San Francisco

Seers, Dudley, 1972, 'The Prevalence of PseudoPlanning', in M. Faber and D. Seers (eds.), The Crisis in Planning, vol. I, Chatto and Windus, London

Stolper, W., 1966, Planning without Facts, Harvard University Press, Cambridge (Mass.)

Wakely, Patrick, Hartmut Schmetzer, and Babar K. Mumtaz (eds.), 1976, Urban Homsing Strategies: Education and Realisation, Pitman, London

Waterston, Albert, 1965, Development Planning: Lessons of Experience, Johns Hopkins University Press, Baltimore 